\title{
Potential of calcium carbonate as secondary filler in eggshell powder filled recycled polystyrene composites
}

\author{
Nabil Hayeemasae ${ }^{*}$ (D) and Hanafi Ismail|2 \\ ${ }^{1}$ Department of Rubber Technology and Polymer Science, Faculty of Science and Technology, Prince of \\ Songkla University, Pattani Campus, Pattani, Thailand \\ ${ }^{2}$ School of Materials and Mineral Resources Engineering, Engineering Campus, Universiti Sains \\ Malaysia, Nibong Tebal, Penang, Malaysia \\ *nabil.h@psu.ac.th
}

\begin{abstract}
Recycling of plastic waste is considered a key intention in regards to the continuous growth of plastic industry. In this work, new composite based on recycled polystyrene (R-PS) was prepared in the presence of eggshell powder (ESP). This was to make a value-added plastic material based on polystyrene. To further extend its performance, calcium carbonate $\left(\mathrm{CaCO}_{3}\right)$ was used as secondary filler to optimize its performance. It is observed that the stabilization torque of composites decreased with increasing the weight percent of $\mathrm{CaCO}_{3}$. Increasing the amount of $\mathrm{CaCO}_{3}$ has increased the mechanical properties such as Young's modulus, tensile strength, elongation at break and impact strength of the composites. These findings corresponded well to SEM images. It revealed homogenous dispersions of $\mathrm{CaCO}_{3}$ throughout R-PS matrix in comparison to ESP alone which formed agglomerations in R-PS matrix. Further evidence on thermal stability has confirmed that $\mathrm{CaCO}_{3}$ provided better heat resistance over the ESP.
\end{abstract}

Keywords: polystyrene, calcium carbonate, eggshell powder, composites.

How to cite: Hayeemasae, N., \& Ismail, H. (2021). Potential of Calcium Carbonate as Secondary Filler in Eggshell Powder Filled Recycled Polystyrene Composites. Polimeros: Ciência e Tecnologia, 31(1), e2021006. https://doi. org/10.1590/0104-1428.09720

\section{Introduction}

Polystyrene is one of the most widely used plastics in many applications i.e., food packaging, home appliance, consumer goods and so forth. Polystyrene is similar to other types of plastic which is non-degradable after use. The abundant of these products has brought to several environmental issues. Therefore, special attention is devoted to recycling, reuse, and making them biodegradable by various approaches ${ }^{[1,2]}$. The first approach is considered to be most possible way to reduce the discarded polystyrene. To date, the recycling of polystyrene mainly includes mechanical, thermal and chemical methods. The mechanical recycling is one among the methods that has a cost-effective and good environmental option. This technique deals with grinding the polystyrene waste and reprocesses into a new raw material. However, the products obtained from this process still possesses low mechanical properties due to degradation aspect $t^{[3-5]}$. Hence, recycled polystyrene with remarkable performance was to develop to overcome this situation while prevailing sustainability.

Introducing fillers to the recycled plastics is another route to increase some properties to the composite. There are two main types of fillers available in the plastic industry which are reinforcing and non-reinforcing fillers. Reinforcing fillers are used to improve the strength and abrasion resistance to the composites ${ }^{[6]}$. However, for some cases where cost

and processability are essential, the use of non-reinforcing fillers are suggested. Calcium carbonate $\left(\mathrm{CaCO}_{3}\right)$ is a good example of non-reinforcing fillers that has been widely used in plastics. For instance, polypropylene ${ }^{[7]}$, polyethylene ${ }^{[8]}$, polystyrene ${ }^{[9]}$ and so forth. It can be said that $\mathrm{CaCO}_{3}$ is still a filler of choice in plastic industry. However, the advancement of plastic technology introduces a new era in the environmental and industrial field of green research. Therefore, searching for an alternative source of filler that is chemically similar to $\mathrm{CaCO}_{3}$ is challenging in the near future.

Traditionally, most eggshell waste is discarded to landfills without further processing. For economic aspects, eggshell waste can be used to convert biomaterials into commercial products and creates new values from these waste materials. It is known that eggshell waste contains lots of valuable organic and inorganic components which can be used in many applications. The chemical composition (by weight) of eggshell has been reported to consist mainly of a mineral part $(95 \%)$ of calcite crystals and a pervading organic matrix (1-3.5\% of the remaining material) ${ }^{[10-13]}$. Thus, it can be considered a good source of $\mathrm{CaCO}_{3}$. Since $\mathrm{CaCO}_{3}$ is by far an important and the most widely used filler because of its whiteness, low abrasion, availability in wide-size ranges and low cost. Consequently, If the eggshell is prepared properly, it is not only a filler added to reduce costs but today it is 
the material engineering for the different requirements of modern products

Despite replacing the $\mathrm{CaCO}_{3}$, the point of application of chicken eggshell waste was to ensure that hybrid fillers based on these two fillers would be able to provide synergistic properties. To date, there has been a limited report on the properties of $\mathrm{ESP} / \mathrm{CaCO}_{3}$ hybrid filled R-PS composites. Due to the above reasons, the effect of $\mathrm{ESP} / \mathrm{CaCO}_{3}$ hybrid fillers on the properties of R-PS composites is thoroughly investigated.

\section{Materials and Methods}

\subsection{Materials}

The materials used for compounding the composites is listed in Table 1. All the materials were used as received except for the eggshell powder (ESP) which was ground until desired particle size.

\subsection{Preparation of Eggshell Powder (ESP)}

The collected chicken eggshell waste was cleaned, washed and dried prior to proceed to the grinding step. The mechanical grinding supplied by Rong Tsong Precision Technology Co. Ltd. was used in the grinding process. The obtained powder form of ESP was sieved using a sieve No. 200 where the size ranging from $30-150 \mu \mathrm{m}$ was used for compounding.

\subsection{Preparation of Composites}

The formulation used for preparing $\mathrm{ESP} / \mathrm{CaCO}_{3}$ hybrid filled R-PS composites is listed in Table 2. ESP and $\mathrm{CaCO}_{3}$ were dried in an oven at $105^{\circ} \mathrm{C}$ for $2 \mathrm{~h}$ before mixing. All the compounding ingredients were melt-mixed in a Thermo HAAKE PolyDrive internal mixer with co-rotating blades. The compounding was carried out at $180^{\circ} \mathrm{C}$ for a total of $8 \mathrm{~min}$ with rotor speed of $60 \mathrm{rpm}$. First, R-PS was charged and ESP and/or $\mathrm{CaCO}_{3}$ was added after 4 min of mixing. The mixing was continued and left for another $4 \mathrm{~min}$. The mixing torques were recorded until dumping out from the internal mixer. Lastly, resultant compounds were weighed at approximately $30 \mathrm{~g}$ and placed inside the mold prior to undergo the compression-molding process using a hydraulic press from GoTech Testing Machines Model KT-7014 A. The compounds were preheated first for $6 \mathrm{~min}$, followed by compression molding for $2 \mathrm{~min}$ at a temperature of $180^{\circ} \mathrm{C}$. The samples were then cooled under pressure for $3 \mathrm{~min}$ at ambient temperature.

\subsection{Measurement of mechanical properties}

Tensile tests were performed using a Universal Testing Machine (UTM) Instron Model 3366 according to the ASTM D638. The samples were pulled at a crosshead speed of 1 $\mathrm{mm} / \mathrm{min}$ with a constant gauge length of $100 \mathrm{~mm}$. The results of the Young's modulus, tensile strength and elongation at break were discussed. As for the impact test, a sample with the dimension of $64 \times 12.7 \times 3.2 \mathrm{~mm}$ was prepared for un-notched Izod impact test. It was carried out using a Zwick Impact Tester Model 5101 according to ASTM D256.

\subsection{Scanning electron microscopy}

The morphological observation was carried out using a scanning electron microscope (SEM) model Zeiss Supra35VP. The samples from the tensile and impact fractures were used to captured the image. It was coated with a layer of gold to prevent an electrostatic charge formation prior to scanning.

\subsection{Thermogravimetric Analysis}

Thermogravimetric analysis of the composites were investigated by a Perkin-Elmer Pyris 6 TGA Analyzer. The sample was heated from $25^{\circ} \mathrm{C}$ to $600^{\circ} \mathrm{C}$ with a heating rate of $10^{\circ} \mathrm{C} / \mathrm{min}$ under a nitrogen atmosphere.

\section{Results and Discussions}

\subsection{Mixing and Stabilization Torque}

Figure 1 shows the processing torque of the R-PS composites at various weight percent of $\mathrm{ESP} / \mathrm{CaCO}_{3}$ hybrid fillers. At initial stage of mixing, the processing torque increased rapidly due to the shearing action from the solid R-PS pellets. Afterwards, the processing torque gradually reduced, indicating a decrease of viscosity as R-PS pellets melt by continuous mechanical shearing and high processing temperature. Then processing torque increase again after 4 min of mixing. This caused by the addition of the ESP and $\mathrm{CaCO}_{3}$ into molten R-PS. The melt viscosity increased in the presence of fillers, which reduced the polymer chain mobility in the blend and consequently raised the processing

Table 1. List of materials used in this study.

\begin{tabular}{|c|c|c|c|}
\hline Materials & Role & Grade/Trade name & Supplier \\
\hline Recycled Polystyrene (R-PS) & Polymer matrix & $\begin{array}{l}\text { rePS- } 5 \text {, the melt flow index of R-PS is } 6.29 \\
\mathrm{~g} / 10 \mathrm{~min}\left(200^{\circ} \mathrm{C} / 5 \mathrm{Kg}\right)\end{array}$ & $\begin{array}{l}\text { Total Petrochemicals Sdn. Bhd., Selangor, } \\
\text { Malaysia }\end{array}$ \\
\hline Eggshell powder (ESP) & Filler & Waste with range of size $30-150 \mu \mathrm{m}$ & Local Restaurant in Penang, Malaysia \\
\hline Calcium Carbonate $\left(\mathrm{CaCO}_{3}\right)$ & Filler & $\begin{array}{l}\text { Ultra-fine precipitated } \mathrm{CaCO}_{3} / \mathrm{MICROMAC} \\
\text { UFC with range of size } 1-10 \mu \mathrm{m}\end{array}$ & Macri Chemicals s.r.1., Milan, Italy \\
\hline
\end{tabular}

Table 2. Composition and mixing sequence of neat R-PS and $\mathrm{ESP} / \mathrm{CaCO}_{3}$ hybrid filled R-PS composites.

\begin{tabular}{cc}
\hline Materials & Composition (wt\%) \\
\hline Neat R-PS & 100 \\
RPS/ESP/CaCO & $80 / 20 / 0,80 / 15 / 5,80 / 10 / 10,80 / 5 / 15,80 / 0 / 20$ \\
\hline
\end{tabular}


torque value ${ }^{[14]}$. The processing torque decreased gradually and the stabilization torque achieved after the composite in homogenized mixture. The similar trend on processing torque was also observed from other literatures with different composites $^{[15,16]}$.

Figure 2 shows the stabilization torque of the R-PS composites at various weight percent of $\mathrm{ESP} / \mathrm{CaCO}_{3}$ hybrid fillers. The results clearly indicate that stabilization torque of composites is decreasing with the increasing the weight percent of $\mathrm{CaCO}_{3}$. Such a decrease in stabilization torque could be due to the fine $\mathrm{CaCO}_{3}$ particles that possesses high dispersibility as compared to ESP. Therefore, $\mathrm{CaCO}_{3}$ was well-dispersed in molten R-PS, resulting lower viscosity found in the composites containing $\mathrm{CaCO}_{3}$. The coarser ESP forms a large network and agglomerates, which required high shear force to disperse the ESP in molten R-PS. Thus, high stabilization torque is observed in the composite based on the ESP alone.

\subsection{Mechanical Properties}

Figure 3 shows the tensile strength of the R-PS composites at various weight percent of $\mathrm{ESP} / \mathrm{CaCO}_{3}$ hybrid fillers. From the result obtained, the tensile strength gradually increased upon increasing the weight percent of $\mathrm{CaCO}_{3}$. The highest tensile strength was observed for the composite containing $20 \mathrm{wt} \%$ of $\mathrm{CaCO}_{3}$. The above results indicate that the

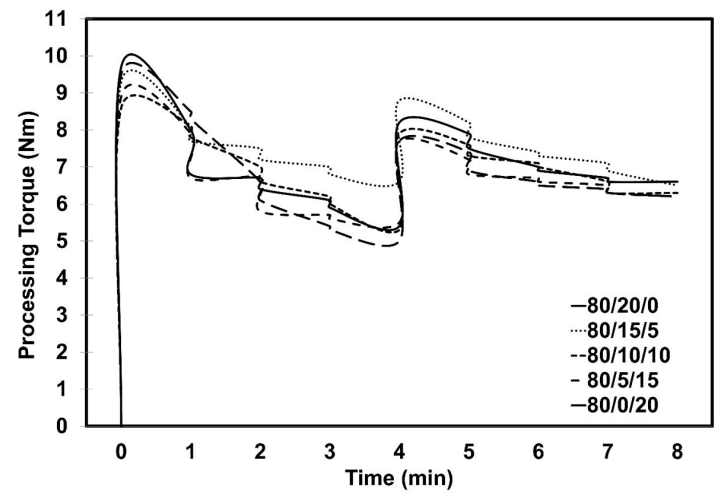

Figure 1. Processing torque as a function of mixing time of ESP/ $\mathrm{CaCO}_{3}$ hybrid filled R-PS composites.

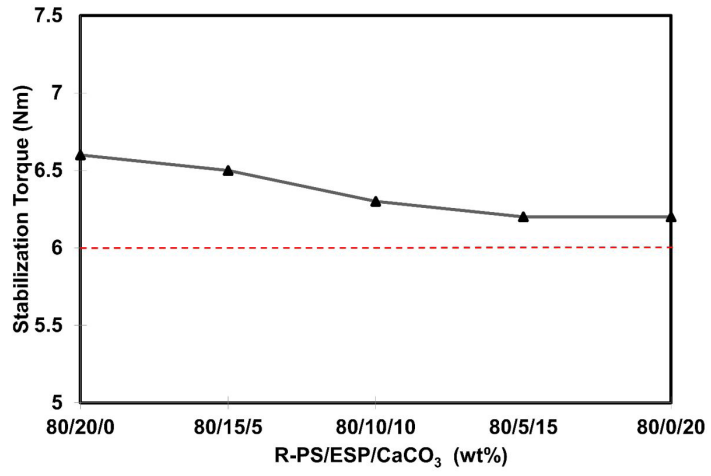

Figure 2. Stabilization torque of $\mathrm{ESP} / \mathrm{CaCO}_{3}$ hybrid filled R-PS composites (Red dash-line is for stabilization torque of neat R-PS). use of $\mathrm{CaCO}_{3}$ led to improve the tensile strength of the composites. This is simply related to the well dispersion of $\mathrm{CaCO}_{3}$ throughout R-PS matrix as compared to ESP which is shown later in SEM images. Strong adhesion between $\mathrm{CaCO}_{3}$ and polymer interface can cause better stress transfer from one to each other. This has led to a higher tensile strength. Toro et al. ${ }^{[17]}$, reported that slightly lower tensile strength of the composite containing solely ESP compared to $\mathrm{CaCO}_{3}$ counterpart can be attributed to its particle size. ESP is normally coaser and bigger size compared with the $\mathrm{CaCO}_{3}$. It is easily agglomerated each other, causing to lower the tensile strength eventually. $\mathrm{CaCO}_{3}$ used in this composite is considered ultra-fine precipitated grade (see Table 1) which has smaller particle size as compared to ESP. The smaller particle size of the filler could produce a maximal interface contact with polymer matrix because of larger specific surface area ${ }^{[18,19]}$. This will improve the wettability of $\mathrm{CaCO}_{3}$ by the R-PS matrix. As a result, a high tensile strength is obtained in composites containing more $\mathrm{CaCO}_{3}$. The location and behaviour of $\mathrm{CaCO}_{3}$ throughout the R-PS matrix can be proved in the SEM micrographs of tensile fractured surfaces in the next section.

Elongation at break of the R-PS composites at various weight percent of $\mathrm{ESP} / \mathrm{CaCO}_{3}$ hybrid fillers is also shown in Figure 3. It can be seen that the elongation at break was increased with the increasing the weight percent of $\mathrm{CaCO}_{3}$. According to literature ${ }^{[17]}$, the increment in elongation at break of the composite can be attributed to the formation of stronger filler aggregates. In this case, it is $\mathrm{CaCO}_{3}$ which is not similar to ESP. ESP is rather found in agglomerated form. The $\mathrm{CaCO}_{3}$ aggregate has better interfacial adhesions with R-PS matrix, resulting in efficient stress transfer from the matrix to filler, thus increasing the elongation at break. The lower flexibility found for the composite containing more ESP can be attributed to extensive ESP agglomeration as mentioned earlier, which transformed into multiple stress concentration sites. Therefore, the crack propagation across the composite could occur on a large scale, prohibiting the composite from dissipating stress in the form of matrix deformations.

Figure 4 shows the Young's modulus of R-PS composites at various weight percent of $\mathrm{ESP} / \mathrm{CaCO}_{3}$ hybrid fillers. Young's modulus of the composites increased as a

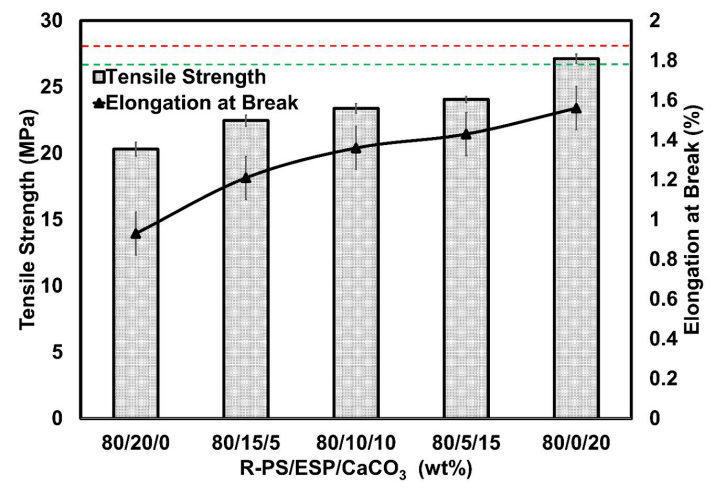

Figure 3. Tensile strength and elongation at break of $\mathrm{ESP} / \mathrm{CaCO}_{3}$ hybrid filled R-PS composites (Red and green dash-lines are for the tensile strength and elongation at break of neat R-PS). 
function of weight percent of $\mathrm{CaCO}_{3}$ due to the increase in the composite's stiffness. According to $\mathrm{Fu}$ et al. ${ }^{[20]}$, Young's modulus is known to be less sensitive variation of interfacial adhesion than the tensile strength which is strongly associated with interfacial failure behaviour. This is due to the fact that Young's modulus is measured before any significant plastic deformation takes place. Increase in tensile modulus of some composite samples is attributed

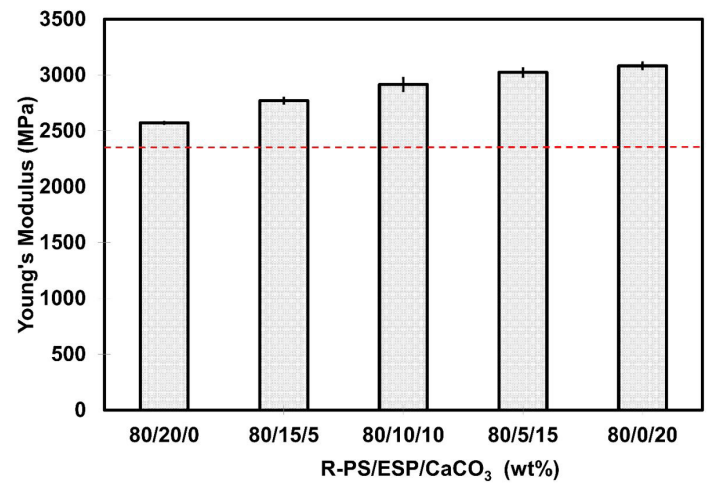

Figure 4. Young's Modulus of $\mathrm{ESP} / \mathrm{CaCO}_{3}$ hybrid filled R-PS composites (Red dash-line is the Young's Modulus of neat R-PS).

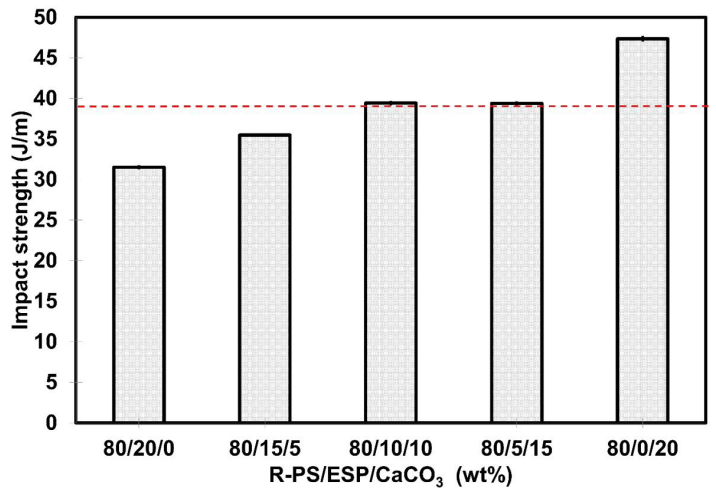

Figure 5. Impact strength of ESP/CaCO 3 hybrid filled R-PS (Red dash-line is the impact strength of neat R-PS). to better distribution of small particle size of $\mathrm{CaCO}_{3}$ in the matrix. A smaller particle size of the $\mathrm{CaCO}_{3}$ could produce a maximal interface contact because of larger specific surface area. The higher surface area of filler gives better adhesion in composite, thus forming a stiffer material which is attributed to higher modulus. Therefore, small particles and homogeneous distribution are the main contribution to originate a more rigid structure.

As for the impact strength (see Figure 5), similar trend was observed. There was an enhancement in impact strength with the addition of $\mathrm{CaCO}_{3}$ to the hybrid composite. This behaviour is similar to a result reported by Bashir et al. ${ }^{[21]}$, considerable improvement in the impact strength of the composite containing $\mathrm{CaCO}_{3}$ as compared to $\mathrm{ESP}$ is mainly due to a well-dispersed $\mathrm{CaCO}_{3}$. This has brought to an increase in the interfacial adhesions between filler and polymer matrix. It is then required higher impact force to overcome the strong interfacial adhesions between $\mathrm{CaCO}_{3}$ within the R-PS matrix. The lower impact strength of the ESP filled composite is simply due to the effect posed by agglomerations of ESP which may act as stress concentration points or points of discontinuity in composites thereby promoting crack initiation and propagation.

\subsection{Morphology}

Figure 6A presents the SEM micrograph of the $\mathrm{CaCO}_{3}$. The shape of the $\mathrm{CaCO}_{3}$ was irregular with various particle sizes. The average particle size of $\mathrm{CaCO}_{3}$ is ranging from $1-10 \mu \mathrm{m}$. It can be seen that there is smaller than the ESP which is in range of $30-150 \mu \mathrm{m}$ (see Figure $6 \mathrm{~B}$ ). This has shown that $\mathrm{CaCO}_{3}$ possesses high possibility to disperse throughout the matrix when compared to ESP.

Figure 7 represents the SEM images obtained from tensile fractured surfaces of $\mathrm{ESP} / \mathrm{CaCO}_{3}$ hybrid filled R-PS composites. Some agglomeration is seen in the composite containing ESP alone (see Figure 7A) and its size was much bigger than the $\mathrm{CaCO}_{3}$ found in Figures $7 \mathrm{~B}$ and $7 \mathrm{C}$. The agglomeration of ESP indicates poor dispersion of ESP throughout the R-PS matrix. The agglomerates and bigger particle of ESP may act as stress concentration points or points of discontinuity in composites thereby inhibiting stress

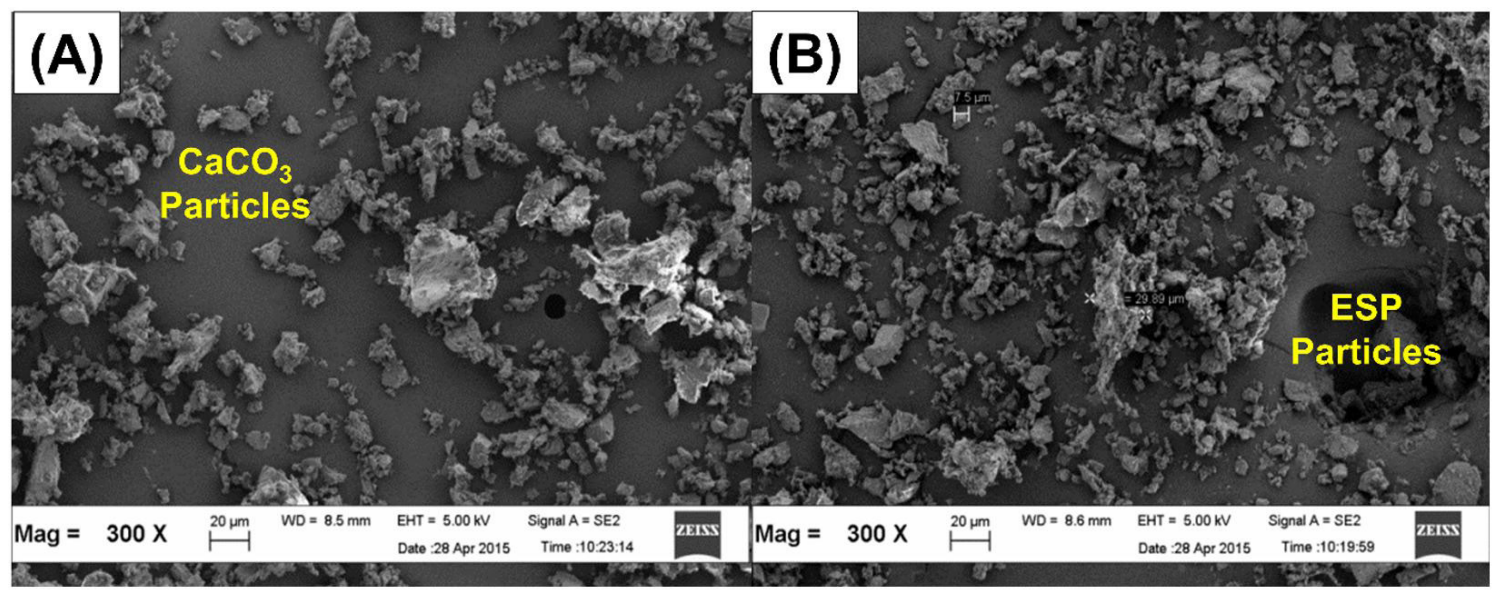

Figure 6. SEM images of raw $\mathrm{CaCO}_{3}$ and ESP. 


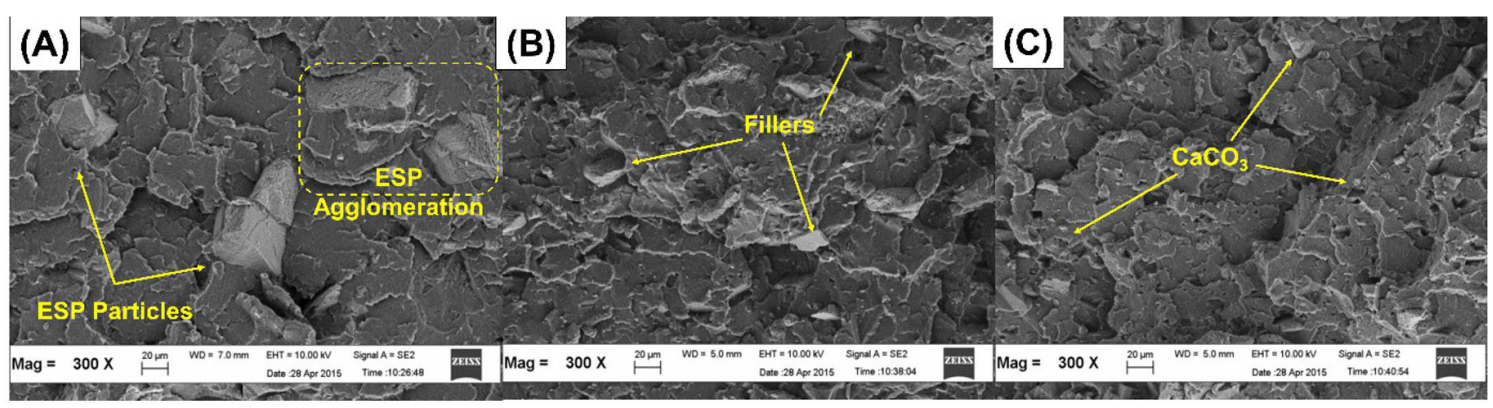

Figure 7. Tensile fractured surfaces of $\mathrm{ESP} / \mathrm{CaCO}_{3}$ hybrid filled R-PS composites at $300 \times$ magnification. $80 / 20 / 0 \mathrm{wt} \%$ (A), $82 / 10 / 10 \mathrm{wt} \%$ (B) and $80 / 0 / 20 \mathrm{wt} \%$ of $\mathrm{R}-\mathrm{PS} / \mathrm{ESP} / \mathrm{CaCO}_{3}$ respectively.

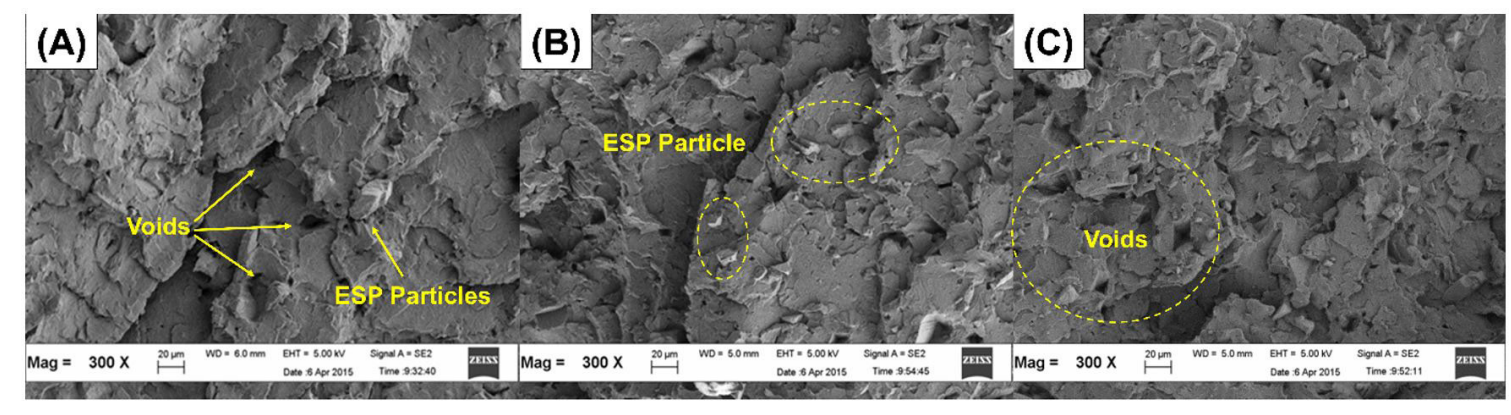

Figure 8. Impact fractured surfaces of $\mathrm{ESP} / \mathrm{CaCO}_{3}$ hybrid filled R-PS composites.at $300 \times$ magnification. 80/20/0 wt $\%$ (A), 82/10/10 wt $\%$ (B) and $80 / 0 / 20 \mathrm{wt} \%$ of $\mathrm{R}-\mathrm{PS} / \mathrm{ESP} / \mathrm{CaCO}_{3}$ respectively.

transfer and reduced the tensile strength of ESP composite. Furthermore, the surface was found to be rougher especially at higher weight ratio of $\mathrm{CaCO}_{3}$, this reflects less brittle deformation and higher energy absorption is generated. Therefore, a higher tensile strength is obtained in composite containing more $\mathrm{CaCO}_{3}$. The SEM results for the tensile fractured surfaces were in good agreement with the results obtained by Siriwardena et al. ${ }^{[22]}$, who reported that an increase in energy was responsible for the roughness and the matrix tearing line of the fractured surface.

Figure 8 demonstrates the SEM images obtained from impact fractured surfaces of $\mathrm{ESP} / \mathrm{CaCO}_{3}$ hybrid filled R-PS composites. Figure 8A shows the SEM image of the R-PS composite containing $20 \mathrm{wt} \%$ of ESP. It exhibits a rough surface with bigger particle of ESP, indicating its poor dispersion in R-PS matrix. This may have brought to a stress concentration points or points of discontinuity in composites thereby promoting crack initiation and propagation. Thus the impact strength of composites is reduced. The image also displays several occurrences of voids due to pullingout of the ESP. Comparing with the composites containing higher weight percent of $\mathrm{CaCO}_{3}$ (see Figures $8 \mathrm{~B}$ and $8 \mathrm{C}$ ), it exhibited less void formation, better dispersion and adhesion of $\mathrm{CaCO}_{3}$ throughout the R-PS matrix. Such remarkable interfacial adhesions of $\mathrm{CaCO}_{3}$ to the R-PS matrix allowed impact force to be absorbed and transferred more uniformly throughout the composite system, thus providing higher impact strength compared to the composite with ESP alone.

\subsection{Thermogravimetric Analysis}

Thermogravimetric analysis or TGA is a method to determine the rate of the weight changes as a function of temperature at a controlled atmosphere. TGA is primarily used to analyse the compositions and thermal stability of materials ${ }^{[23]}$. The thermograms (TG) and derivative thermograms (DTG) of ESP/ $\mathrm{CaCO}_{3}$ hybrid filled R-PS composites are shown in Figure 9. The decomposition temperature at $50 \%\left(\mathrm{~T}_{50 \%}\right)$ mass loss, maximum mass loss $\left(\mathrm{T}_{\text {max }}\right)$ and char residue are also listed in Table 3. From the results obtained, there is only one region of the thermogram observed. The degradation started at the temperature around $350^{\circ} \mathrm{C}$ and was then completed at about $450^{\circ} \mathrm{C}$. The decomposition was mainly due to the degradation of polystyrene segment where it corresponds to the major peak observed off the DTG curve (see the DTG peaks embedded in Figure 9).

To compare the results, the temperature for $50 \%$ mass loss was determined as degradation temperature of the composite. The R-PS composites with $20 \mathrm{wt} \%$ of $\mathrm{CaCO}_{3}$ had a highest degradation temperature of $\mathrm{T}_{50 \%}\left(425.93{ }^{\circ} \mathrm{C}\right)$ as compared to the other composite. This is simply due to the presence of well-dispersed $\mathrm{CaCO}_{3}$ in R-PS matrix, which is expected to provide a barrier to the diffusion of degradation products, suppressing R-PS mass loss in the composite. The balance set of thermal stability is served for the composite with $10 \mathrm{wt} \%$ of ESP and $\mathrm{CaCO}_{3}$ respectively. This is interesting to highlight that the incorporation of ESP with the assistance of $\mathrm{CaCO}_{3}$ can promote the resistance to heat of R-PS matrix. In addition to that, lowest degradation temperature of $\mathrm{T}_{50 \%}\left(424.11^{\circ} \mathrm{C}\right)$ found in the composite with $20 \mathrm{wt} \%$ of ESP may be due to poor dispersion of ESP in R-PS matrix, arising from the formation of agglomerated ESP which reduced thermal stability of the composites.

The amount of residue of R-PS composites with $20 \mathrm{wt} \%$ of $\mathrm{CaCO}_{3}$ is highest (approximately 20.79\%) among the 
Table 3. Degradation temperatures and weight residue of $\mathrm{ESP} / \mathrm{CaCO}_{3}$ hybrid filled R-PS composites.

\begin{tabular}{lccc}
\multicolumn{1}{c}{ Sample Designation } & $\mathbf{T}_{\mathbf{5 0} \%}\left({ }^{\circ} \mathbf{C}\right)$ & $\mathbf{T}_{\max } / \mathbf{D T G}$ Peak $\left({ }^{\circ} \mathbf{C}\right)$ & Residue (\%) \\
\hline $20 \mathrm{wt} \%$ of ESP & 424.03 & 422.57 & 18.33 \\
$10 / 10 \mathrm{wt} \%$ of $\mathrm{ESP} / \mathrm{CaCO}_{3}$ & 424.11 & 423.48 & 19.49 \\
$20 \mathrm{wt} \%$ of $\mathrm{CaCO}_{3}$ & 425.93 & 424.11 & 20.79 \\
\hline
\end{tabular}

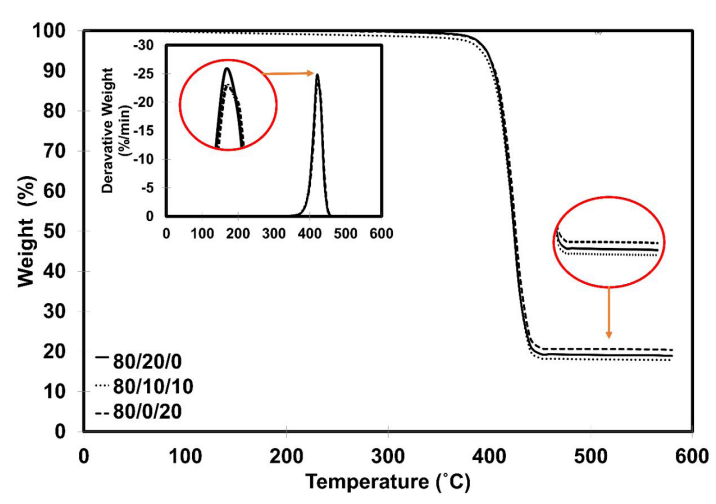

Figure 9. TG and DTG curves of $\mathrm{ESP} / \mathrm{CaCO}_{3}$ hybrid filled R-PS composites.

other composite. This residual value of composite is higher than its filler content because the R-PS matrix may contain thermally stable impurities. R-PS composite with $20 \mathrm{wt} \%$ of ESP has lower residue content (roughly 19.49\%) than $20 \mathrm{wt} \%$ of $\mathrm{CaCO}_{3}$ composite. This is attributed to the loss of organic composition during or after testing.

\section{Conclusions}

The processability, mechanical, morphological, and thermal properties of $\mathrm{ESP} / \mathrm{CaCO}_{3}$ hybrid filled R-PS composites were studied with respect to different weight percent of $\mathrm{ESP} / \mathrm{CaCO}_{3}$ hybrid fillers. It is found that the stabilization torque of composites was decreased with the increased of the amount of $\mathrm{CaCO}_{3}$. Increasing $\mathrm{CaCO}_{3}$ content has increased tensile strength, elongation at break, Young's modulus, and impact strength of the composites. The mechanical properties obtained clearly corresponded to SEM images observed. Further evidence on the thermal stability has confirmed that $\mathrm{CaCO}_{3}$ provided better heat resistance over the ESP alone. Even the $\mathrm{CaCO}_{3}$ seemed to play important role in the properties of $\mathrm{ESP} / \mathrm{CaCO}_{3}$ hybrid filled R-PS composites. However, the hybridization of ESP and $\mathrm{CaCO}_{3}$ does show balance set of properties especially the mechanical and thermal properties of $\mathrm{ESP} / \mathrm{CaCO}_{3}$ hybrid filled R-PS composites. It can be concluded that the ESP hybridized $\mathrm{CaCO}_{3}$ is applicable to prepare the composite based on the R-PS where the ratio of ESP and $\mathrm{CaCO}_{3}$ at $10 / 10(w t \%)$ is highly suggested.

\section{References}

1. Pimentel, T. A. P. F., Durães, J. A., Drummond, A. L., Schlemmer, D., Falcão, R., \& Sales, M. J. A. (2007). Preparation and characterization of blends of recycled polystyrene with cassava starch. Journal of Materials Science, 42(17), 7530-7536. http:// dx.doi.org/10.1007/s10853-007-1622-x.
2. Gutiérrez, C., García, M. T., Gracia, I., de Lucas, A., \& Rodríguez, J. F. (2012). Recycling of extruded polystyrene wastes by dissolution and supercritical CO2 technology. Journal of Material Cycles and Waste Management, 14, 308316. http://dx.doi.org/10.1007/s10163-012-0074-9.

3. Borsoi, C., Scienza, L. C., \& Zattera, A. J. (2013). Characterization of composites based on recycled expanded polystyrene reinforced with curaua fibers. Journal of Applied Polymer Science, 128(1), 653-659. http://dx.doi.org/10.1002/app.38236.

4. Lisperguer, J., Bustos, X., \& Saravia, Y. (2011). Thermal and mechanical properties of wood flour-polystyrene blends from postconsumer plastic waste. Journal of Applied Polymer Science, 119(1), 443-451. http://dx.doi.org/10.1002/app.32638.

5. Poletto, M., Dettenborn, J., Zeni, M., \& Zattera, A. J. (2011). Characterization of composites based on expanded polystyrene wastes and wood flour. Waste Management (New York, N.Y.), 31(4), 779-784. http://dx.doi.org/10.1016/j.wasman.2010.10.027. PMid:21172732.

6. Kourki, H., Famili, M. H. N., Mortezaei, M., \& Malekipirbazari, M. (2018). Mixing challenges for $\mathrm{SiO} 2 /$ polystyrene nanocomposites. Journal of Thermoplastic Composite Materials, 31(5), 709-726. http://dx.doi.org/10.1177/0892705717718599.

7. Chan, C.-M., Wu, J., Li, J.-X., \& Cheung, Y.-K. (2002). Polypropylene/calcium carbonate nanocomposites. Polymer, 43(10), 2981-2992. http://dx.doi.org/10.1016/S00323861(02)00120-9.

8. Bartczak, Z., Argon, A. S., Cohen, R. E., \& Weinberg, M. (1999). Toughness mechanism in semi-crystalline polymer blends: II. High-density polyethylene toughened with calcium carbonate filler particles. Polymer, 40(9), 2347-2365. http:// dx.doi.org/10.1016/S0032-3861(98)00444-3.

9. Suetsugu, Y., \& White, J. L. (1983). The influence of particle size and surface coating of calcium carbonate on the rheological properties of its suspensions in molten polystyrene. Journal of Applied Polymer Science, 28(4), 1481-1501. http://dx.doi. org/10.1002/app.1983.070280421.

10. Ghabeer, T., Dweiri, R., \& Al-Khateeb, S. (2013). Thermal and mechanical characterization of polypropylene/eggshell biocomposites. Journal of Reinforced Plastics and Composites, 32(6), 402-409. http://dx.doi.org/10.1177/0731684412470015.

11. Sutapun, W., Pakdeechote, P., Suppakarn, N., \& Ruksakulpiwat, Y. (2013). Application of Calcined Eggshell Powder as Functional Filler for High Density Polyethylene. PolymerPlastics Technology and Engineering, 52(10), 1025-1033. http://dx.doi.org/10.1080/03602559.2013.769578.

12. Toro, P., Quijada, R., Arias, J. L., \& Yazdani-Pedram, M. (2007). Mechanical and morphological studies of poly(propylene)filled eggshell composites. Macromolecular Materials and Engineering, 292(9), 1027-1034. http://dx.doi.org/10.1002/ mame.200700147.

13. Feng, Y., Ashok, B., Madhukar, K., Zhang, J., Zhang, J., Reddy, K. O., \& Rajulu, A. V. (2014). Preparation and Characterization of Polypropylene Carbonate Bio-Filler (Eggshell Powder) Composite Films. International Journal of Polymer Analysis and Characterization, 19(7), 637-647. http://dx.doi.org/10.1 080/1023666X.2014.953747.

14. Halimatudahliana, A., Ismail, H., \& Nasir, M. (2002). Morphological studies of uncompatibilized and compatibilized 
polystyrene/polypropylene blend. Polymer Testing, 21(3), 263-267. http://dx.doi.org/10.1016/S0142-9418(01)00079-4.

15. Gallagher, L. W., \& McDonald, A. G. (2013). The effect of micron sized wood fibers in wood plastic composites. Maderas. Ciencia y Tecnología, 15(ahead), 357-374. http:// dx.doi.org/10.4067/S0718-221X2013005000028.

16. Sarifuddin, N., \& Ismail, H. (2013). Comparative study on the effect of Bentonite or Feldspar Filled Low-Density Polyethylene/Thermoplastic Sago Starch/Kenaf Core Fiber Composites. BioResources, 8(3), 4238-4257. http://dx.doi. org/10.15376/biores.8.3.4238-4257.

17. Toro, P., Quijada, R., Yazdani-Pedram, M., \& Arias, J. L. (2007). Eggshell, a new bio-filler for polypropylene composites. Materials Letters, 61(22), 4347-4350. http://dx.doi.org/10.1016/j. matlet.2007.01.102.

18. Tanaka, H., \& White, J. L. (1980). Experimental investigations of shear and elongational flow properties of polystyrene melts reinforced with calcium carbonate, titanium dioxide, and carbon black. Polymer Engineering and Science, 20(14), 949-956. http://dx.doi.org/10.1002/pen.760201406.

19. Ismail, H., Awang, M., \& Hazizan, M. A. (2006). Effect of waste tire dust (WTD) size on the mechanical and morphological properties of polypropylene/waste tire dust (PP/WTD) blends. Polymer-Plastics Technology and Engineering, 45(4), 463-468. http://dx.doi.org/10.1080/03602550600553739.
20. Fu, S. Y., Feng, X. Q., Lauke, B., \& Mai, Y.-W. (2008). Effects of particle size, particle/matrix interface adhesion and particle loading on mechanical properties of particulate-polymer composites. Composites. Part B, Engineering, 39(6), 933-961. http://dx.doi.org/10.1016/j.compositesb.2008.01.002.

21. Bashir,A. S. M., \& Manusamy, Y. (2015). Recent Developments in Biocomposites Reinforced with Natural Biofillers from Food Waste. Polymer-Plastics Technology and Engineering, 54(1), 87-99. http://dx.doi.org/10.1080/03602559.2014.9354 19.

22. Siriwardena, S., Ismail, H., \& Ishiaku, U. S. (2000). Effect of mixing sequence in the preparation of white rice husk ash filled polypropylene/ethylene-propylene-diene monomer blend. Polymer Testing, 20(1), 105-113. http://dx.doi.org/10.1016/ S0142-9418(00)00008-8.

23. Nabil, H., \& Ismail, H. (2014). Enhancing the thermal stability of natural rubber/recycled ethylene-propylene-diene rubber blends by means of introducing pre-vulcanised ethylenepropylene-diene rubber and electron beam irradiation. Materials \& Design, 56, 1057-1067. http://dx.doi.org/10.1016/j. matdes.2013.12.020.

Received: Nov. 01, 2020

Revised: Jan. 19, 2021

Accepted: Feb. 24, 2021 